\title{
LOS HELECHOS MEDICINALES DE CHILE Y SUS NOMBRES VULGARES ${ }^{1}$
}

\section{CHILEAN MEDICINAL FERNS AND THEIR POPULAR NAMES}

\author{
Gualterio Looser† \& Roberto Rodríguez ${ }^{2}$ \\ $†$ Fallecido en 1982 \\ ${ }^{2}$ Departamento de Botánica, Facultad de Ciencias Naturales y Oceanográficas, Universidad de Concepción, Casilla \\ 160 C, Concepción, Chile. e-mail: rrodrigu@udec.cl
}

RESUMEN

Se presenta un manuscrito inédito del naturalista Gualterio Looser (1886-1982), sobre los helechos medicinales de Chile y sus nombres vulgares. Se agregan nombres científicos actuales, se detallan las citas bibliográficas y se actualiza la ortografía. El documento original se encuentra archivado en la biblioteca del Departamento de Botánica, Universidad de Concepción.

Palabras Claves: Adiantaceae, Blechnaceae, Dicksoniaceae, Dryopteridaceae, Equisetaceae, etnobotánica, Gleicheniaceae, Polypodiaceae.

\section{ABSTRACT}

This paper presents a previously unpublished manuscript by the naturalist Gualterio Looser (1886-1982), on Chilean medicinal ferns and their popular names. Current scientific names are added, bibliographic references are given in full, and spelling modernized. The original document is archived in the library of the Department of Botany,

Universidad de Concepción.

KeYwords: Adiantaceae, Blechnaceae, Dicksoniaceae, Dryopteridaceae, Equisetaceae, ethnobotany, Gleicheniaceae, Polypodiaceae.

El pueblo chileno es el resultado de la mezcla entre los invasores españoles y los aborígenes. Indios puros casi no quedan y el idioma español domina en forma casi absoluta. Pero su estado cultural es todavía deficiente y el analfabetismo, principalmente en los campos, alcanza elevado porcentaje. Es bastante supersticioso y su fe casi absoluta en brujos, "meicos" y "meicas" sólo es comparable a la des- confianza que siente por la medicina científica. Las plantas chilenas a las cuales se le atribuyen virtudes medicinales suman una cifra elevada y en todas las ciudades de Chile no faltan nunca negocios bastante prósperos donde están en venta estas yerbas milagrosas.

Sin duda alguna, en muchos casos no se puede negar la eficiencia de estos remedios populares,

\footnotetext{
${ }^{1}$ En toda la literatura revisada de las publicaciones del naturalista chileno Gualterio Looser (1886-1982) no aparece concretamente una relación de los helechos chilenos con propiedades medicinales, y en los documentos depositados en la biblioteca del Departamento de Botánica de la Universidad de Concepción se encontró un manuscrito inédito, redactado posiblemente entre los años 1950-1960 donde relata los beneficios que poseen los helechos nativos en la medicina popular y el origen de sus nombres vulgares. Como un homenaje póstumo a su magna obra se da a conocer este manuscrito, interpretando la letra de su artículo lo más fielmente posible, agregando notas pertinentes, en paréntesis cuadrado, acerca de la actualización de los nombres científicos, bibliografía usada por Looser y fechas de publicación. Además se actualiza la clasificación de las especies dentro de sus respectivas familias.

Roberto Rodríguez Ríos.
} 
pero falta todavía un control científico. Aunque en los últimos 50 años las escuelas de farmacia en Chile han hecho valiosas investigaciones sobre varias hierbas chilenas, quedan todavía muchos puntos que aclarar.

En las líneas siguientes me ocuparé brevemente de las pteridófitas chilenas a las cuales se les atribuye poder medicinal, sin, por cierto, hacerme garante de ello.

\section{Familia ADIANTACEAE}

\section{Adiantum chilense Kaulf.}

Helecho bastante frecuente en todo Chile central hasta la Patagonia occidental. Se le llama vulgarmente "culantrillo", palabra española de fina estirpe clásica que se deriva de la misma palabra griega que ha dado origen al cilantro o culantro (Coriandrum sativum). También suele llamársele en Chile "doradilla", pero este nombre es más bien propio de las Notholaena y Cheilanthes. En cambio en Chile no circula el otro nombre español "capilaria", que corresponde al francés capillaire y que podemos traducir libremente al inglés como maidenhair (Frauenhaar de los alemanes). Según Baeza [1930] en el sur de Chile culantrillo se aplica a cualquier helecho pequeño.

Según las investigaciones de Yáñez [1929], Adiantum chilense y también las demás especies chilenas del género que se confunden con el primero (A. scabrum, A. sulphureum, A. excisum, etc.) tiene con la capilaria de la farmacopea europea ( $A$. capillus-veneris) propiedades espectorantes pero no muy enérgicas. La acción medicamenticia parece ser originada por un alcaloide. Tiene también vicina y se ha comprobado la ausencia de glucósido. Gotschlich [1913] dice que el A. chilense en decocción con miel de abejas se administra como pectoral, aperitivo y emenagogo. Santa Cruz [1937] añade que $A$. chilense es abortivo.

\section{Notholaena tomentosa (Desv.) Desv. [= Cheilanthes hypoleuca (Kunze) Mett.]}

Muy común en todo Chile central. Crece en las hendiduras de las rocas asoleadas y no pasa generalmente de $30 \mathrm{~cm}$. Este es quizás el helecho que se vende con más frecuencia en la mayoría de herbolarios de Santiago, quienes lo recomiendan como emenagogo y diurético. Se emplea toda la planta en infusión y figuraba entre las plantas diuréticas de la antigua farmacopea chilena.

Notholaena mollis [= Cheilanthes mollis] se diferencia porque tiene pelos estrellados y tiene las mismas cualidades. Parece que ambas contienen un glucósido.

El nombre vulgar de estas dos especies es "doradilla", que también ha sido aplicado a Cheilanthes glauca, que además pasa por medicinal. Doradilla es palabra española y podría traducirse al inglés como "golden fern". En francés se usa el mismo nombre (doradille) y se le aplica como en Chile a helechos xerófitos (en España y Francia a Ceterach y también a Asplenium).

Troncoso [1937] estableció que además tiene un principio activo de acción antihelmíntica soluble en agua y podría reemplazar el extracto etéreo de helecho macho. No tiene acción tóxica.

\section{Pellaea myrtillifolia Mett. ex Kuhn}

Es una Polypodiaceae [Adiantaceae] bastante escasa de lugares secos que conozco en las provincias de Coquimbo a Colchagua. Se dice que en la provincia de Coquimbo lo toman en infusión para los dolores de estómago. También serviría para el dolor de muela. A su acción calmante se deberá que se le llama vulgarmente coca o "yerba coca" que recuerda a la verdadera coca del Perú (Erythroxylon coca), cuyas hojas sirven para la obtención de la cocaína. También se le llama "lendo del cerro" [Espinosa 1938].

\section{Familia BLECHNACEAE}

Blechnum auriculatum Cav. [= Blechnum hastatum Kaulf.]

Helecho bastante común en lugares frescos de todo Chile central desde la provincia de Coquimbo hasta la Patagonia occidental.

Se llama vulgarmente "palmilla" (= little palm), lo mismo que Lophosoria. Los indios araucanos lo denominan según Gunckel "arri cül 
cül" (datos de herbario). La ü araucana a menudo se transforma en la $i$ española ( $i$ de it en inglés), ü debe pronunciarse como en alemán (über, Müller). Se usa mucho en medicina popular como emenagogo y abortivo.

Es probable que Blechnum chilense (Kaulf.) Mett. tenga cualidades parecidas. Esta se llama vulgarmente en español "costilla de vaca" debido al parecido que presentan sus grandes y anchas frondas con un esqueleto de vacuno. Los indios araucanos lo llaman "cül cül" o "quilquil", nombre que también emplea la gente de idioma español. Este vocablo araucano aparece varias veces en la toponimia, por ejemplo Quilquilco (co $=$ agua o río).

Muy parecido pero más grande es Blechnum magellanicum (Desv.) Mett. y que sería útil para las enfermedades a la vista, lo mismo que B. chilense. Según Spegazzini [18961897] los indios onas y yaganes de Tierra del Fuego y que hoy están casi extinguidos llaman "kättälapi" al B. magellanicum.

\section{Familia DICKSONIACEAE}

Lophosoria quadripinnata (Gmel.) C. Chr.

Este gran helecho, de vasta repartición por las Américas desde México al Brasil, abunda mucho en las regiones boscosas del sur de Chile, donde se le conoce vulgarmente como "palmita" y "helecho de Valdivia", por ser particularmente abundante en la provincia de este nombre. Lleva, además, el nombre indígena de "ampe", que sin duda es araucano. Según Valenzuela [19181919] vendría de ampin, remedio. En efecto, ampin significa en araucano aplicar remedio de polvo o yerba quemada a la piel, lo que tal vez se refiera a sus efectos comprobados de hemostático.

El abundante vello que cubre la base de las frondas y rizomas es hemostático poderoso de cualidades parecidas al "penawar djambi" producido por el gran helecho Cibotium barometz de los trópicos asiáticos. En 1879, durante la guerra entre Chile y Perú, el intendente de Llanquihue remitió varios cajones de pelos de Lophosoria al servicio del Ejército chileno, que le dio las gracias reconociendo su buen efecto.
Murillo [1889] dice que siempre le dio buen resultado para detener hemorragias producidas por picaduras de sanguijuelas o heridas pequeñas.

\section{Familia DRYOPTERIDACEAE}

Polystichum adiantiforme (G.Forster) J.Sm. [= Rumohra adiantiformis (G.Forster) Ching]

Remy [1854] escribió hace casi un siglo que Polystichum coriaceum Schott, sinónimo de Polystichum adiantiforme llevaba en Chile los nombres vulgares de "calahuala" y "yerba del lagarto", iguales a los de Polypodium feuillei, lo que se debiera a su rizoma rastrero que se le parece bastante. Dice que la raíz es muy usada como aperitiva, sudorífica y resolutiva. Nada dicen los naturalistas posteriores y parece que ha sido olvidada. Philippi [1869] cree que pueda haber confusión con el Polypodium feuillei.

\section{Familia EQUISETACEAE}

\section{Equisetum bogotense Kunth}

Es un pariente primitivo de los helechos con una amplia distribución desde América Central hasta el extremo austral de Sudamérica, viviendo en ambientes muy húmedos especialmente a la orilla de los cursos de agua. Por su aspecto ramificado con abundantes ramas delgadas, con nudos $\mathrm{y}$ entrenudos notorios, ha recibido el nombre científico de Equisetum (del latín equus, caballo, y seta, cerda o crin, la planta recuerda una cola de caballo) y su epíteto específico alude a la ciudad colombiana de donde proviene el material con que fue descrita por primera vez.

En el país se le conoce como "limpiaplata", "yerba del platero", "yerba de la plata", debido a la aspereza de sus tallos que contienen sales de sílice y sirve para pulir metales, especialmente objetos de plata [Baeza 1930]. Según Gunckel [1959] los indígenas le llaman "kelwi-lawen" y "winal".

Muy apreciada en medicina popular chilena, se recomienda la infusión teiforme contra los cálculos vesicales y renales. Considerada un buen diurético y parece tener cierta acción astringente 
útil en las disenterías. Según Duvauchelle (1923), contiene anhidrido silícico y ácido equisético. No contiene alcaloide, goma, resina ni tanino. La farmacología de la planta se debería a la gran cantidad de sílice que contiene.

\section{Familia GLEICHENIACEAE}

Dicranopteris squamulosa (Desv.) Loos. [= Gleichenia squamulosa (Desv.) T. Moore]

Este helecho se extiende desde la provincia de Maule hasta las islas Chonos, en la Patagonia occidental. Abunda mucho en ciertas regiones, como en las provincias de Valdivia, Llanquihue y Chiloé, y lleva el nombre español de "yerba loza", quizá debido a sus frondas quebradizas. Se dice que tendría excelentes cualidades estomacales y sería muy usado con fines medicinales junto con la especie muy afín $D$. quadripartita (Poir.) Loos. [= Gleichenia quadipartita]. Domínguez [cita no ubicada] nos informa que el "wedawe" (Dicranopteris sp. [= Gleichenia sp.]) era un afrodisíaco de los araucanos. Wedawe es palabra araucana y Félix José de Augusta [1916], en su diccionario de este idioma aborigen, dice que se trata de las especies Dicranopteris litoralis (Phil.) Looser [= Gleichenia litoralis] y $D$. squamulosa [= Gleichenia squamulosa] y les atribuye la virtud de separar del rival el afecto de la persona querida e, indudablemente, el vocablo wedawe está emparentado con el verbo araucano wedan, que significa separarse, partirse, dividirse.

\section{Familia POLYPODIACEAE}

\section{Polypodium feuillei Bertero}

Este es quizá el helecho más afamado de la medicina popular chilena, lo que se manifiesta en que tiene nada menos de tres nombres vulgares muy divulgados:

1. "Calahuala" (o "calaguala"), vocablo que según Lenz [1905-1910] quizá pertenezca al idioma quechua del Perú. Una especie peruana se llama en botánica Polypodium calaguala Ruiz y antes se exportaba a Europa como planta medicinal. En opinión de Valenzuela [1918-1919] calahuala viene del quechua "kala", pelado y "huaylla", pasto verde, de modo que su significado sería pasto verde pelado. Herrera [1939] sostiene también que se trata de un vocablo quechua. La palabra calahuala se ha divulgado mucho y es usada prácticamente en toda la América española, por ejemplo en México se aplica a Polypodium aureum y a otras especies del mismo género.

2. "Vilcún" o más bien "pillavilcún". Actualmente sólo se dice "vilcún", vocablo que en araucano significa lagarto; pero seguramente el nombre original era pillavilcún, lo que significa planta (o hierba) del lagarto, pues los diccionarios traducen la palabra araucana "pilla" como "cierta planta". El nombre pillavilcún aparece ya en Feuillée [17141725], hace más de dos siglos, quien dio la primera descripción científica de esta planta: Polypodium radice squamoso vulgo pillabilcum.

3. "Yerba del lagarto". Este es el nombre que hoy día se usa con más frecuencia para este helecho $\mathrm{y}$, como puede verse, por el párrafo anterior, es simplemente la traducción al castellano del nombre primitivo en idioma araucano o mapuche, que se hablaba antes en todo Chile central desde el sur de la provincia de Coquimbo hasta Chiloé. El nombre de yerba del lagarto es bastante apropiado, pues los largos rizomas gruesos, carnosos y escamosos de este helecho, se arrastran como lagartos sobre los troncos de los grandes árboles forestales.

El rizoma de Polypodium feuillei se usa en infusión o decocto en las afecciones pulmonares crónicas, coqueluches, catarros gástricos y cólicos. Pasa por ser un vulnerario tan apreciado por algunos como el árnica. También se le considera depurativo y sudorífico y se le atribuyen propiedades temperantes, resolutivas y pectorales.

Según González [1940], este helecho tiene propiedades antihelmínticas pero en proporción bastante inferior a las del helecho macho [Dryopteris filix-mas]. Sin embargo, estas propiedades no son aprovechadas por la medicina popular.

\section{AGRADECIMIENTOS}

A la familia Looser por la donación de parte de la biblioteca de don Gualterio Looser, al Departamento de Botánica de la Universidad de Concepción, al Proyecto Flora de Chile por el apoyo bibliográfico y al Prof. Clodomiro Marticorena por las sugerencias y correcciones a este trabajo. 


\section{BIBLIOGRAFIA}

Augusta, F.J. DE. 1916. Diccionario Araucano-Español y Español-Araucano. 2 vols. Imprenta Universitaria, Santiago de Chile. 172 pp.

BAEZA, V.M. 1930. Los nombres vulgares de las plantas silvestres de Chile y su concordancia con los nombres científicos. Y observaciones sobre la aplicación técnica y medicinal de algunas especies. 2a. edición aumentada con nuevos nombres y el significado etimológico de los nombres científicos. Imprenta El Globo. Santiago de Chile. 270 pp.

Duvauchelle, C.L. 1923. Estudio químico del Equisetum bogotense. Tesis, Escuela de Farmacia, Universidad de Concepción, Chile.

Espinosa, M.R. 1938. El Prof. Espinosa leyó sus Apuntes Botánicos ... [Acta de la cuarta sesión, Sociedad Chilena de Historia Natural]. Revista Chilena de Historia Natural 42: 399.

FeuilLÉE, L.E. 1714-1725. Journal des observations physiques, mathematiques et botaniques. Faites par l'ordre du Roy sur les côtes orientales de l'Amerique meridionale, \& dans les Indies Occidentales, depuis l'année 1707 jusques en 1712. Paris. 3 vols.

GonzÁlez, J.E. 1940. Estudio botánico y químico del Polypodium sinammia. Tesis, Escuela de Química y Farmacia, Universidad de Chile. 25 pp.

Gotschlich, B. 1913. Llanquihue y Valdivia. Boletín del Museo Nacional de Chile 6: 7-626.

GunCKeL, H. 1959. Nombres indígenas relacionados con la flora chilena. Boletín de Filología 11: 191-327.
Herrera, F.L. 1939. Catálogo alfabético de los nombres vulgares y científicos de plantas que existen en el Perú. Universidad Mayor de San Marcos, Lima, Perú. 363 pp.

LENZ, R. 1905-1910. Los elementos indios del castellano de Chile. Estudio lingüístico i etimolójico. Diccionario etimolójico de las voces chilenas derivadas de lenguas indíjenas americanas. Imprenta Cervantes. Santiago de Chile.

Murillo, A. 1889. Plantes médicinales du Chili. Exposition Universelle de Paris, Paris. xii, 234 pp.

PhiLIPPI, R.A. 1869. Elementos de botánica para el uso de los estudiantes de medicina i farmacia en Chile. Imprenta Nacional, Santiago de Chile. 571 pp.

Remy, J. 1854. Helechos. En: Flora de Chile, vol. 6 (ed. C. Gay), pp. 473-542.

SANTA Cruz, A. 1937. Las plantas mágicas mapuches. Revista Chilena de Historia Natural 41: 172-177.

SpegazZINI, C. 1896-1897. Plantae per Fuegiam a Carolo Spegazzini anno 1882 collectae. Anales del Museo Nacional de Buenos Aires 5 (ser. 2:2): 39 104.

Troncoso, E. 1937. Estudio químico y experimentación biológica de la Nothochlaena hipoleuca (Doradilla). Tesis, Escuela de Farmacia, Universidad de Chile. 35 pp.

Valenzuela, P.A. 1918-1919. Glosario etimológico de nombres de hombres, animales, plantas, ríos y lugares, y vocablos incorporados en el lenguaje vulgar, aborígenes de Chile, y de algún otro país americano. 2 vols. Imprenta Universitaria, Santiago de Chile.

YÁÑEz, M. 1929. Adiantum chilensis, estudio de sus propiedades. Tesis, Escuela de Farmacia, Universidad de Concepción. 27 pp.

Fecha de recepción: 26.09.03

Fecha de aceptación: 10.03.04 